American J. of Engineering and Applied Sciences 3 (1): 42-48, 2010

ISSN 1941-7020

(C) 2010 Science Publications

\title{
New Control Technique Applied in Dynamic Voltage Restorer for Voltage Sag Mitigation
}

\author{
${ }^{1}$ Rosli Omar, ${ }^{2}$ Nasrudin Abd Rahim and ${ }^{3}$ Marizan Sulaiman \\ ${ }^{1}$ Faculty of Electrical Engineering, Technical University, Malaysia Malacca, Malacca, Malaysia \\ ${ }^{2}$ Department of Electrical Engineering, Faculty of Engineering, Kuala Lumpur, Malaysia \\ ${ }^{3}$ Faculty of Electrical Engineering, Technical University Malaysia Malacca, Malacca, Malaysia
}

\begin{abstract}
The Dynamic Voltage Restorer (DVR) was a power electronics device that was able to compensate voltage sags on critical loads dynamically. The DVR consists of VSC, injection transformers, passive filters and energy storage (lead acid battery). By injecting an appropriate voltage, the DVR restores a voltage waveform and ensures constant load voltage. There were so many types of the control techniques being used in DVR for mitigating voltage sags. The efficiency of the DVR depends on the efficiency of the control technique involved in switching the inverter. Problem statement: Simulation and experimental investigation toward new algorithms development based on SVPWM. Understanding the nature of DVR and performance comparisons between the various controller technologies available. The proposed controller using space vector modulation techniques obtain higher amplitude modulation indexes if compared with conventional SPWM techniques. Moreover, space vector modulation techniques can be easily implemented using digital processors. Space vector PWM can produce about 15\% higher output voltage than standard Sinusoidal PWM. Approach: The purpose of this research was to study the implementation of SVPWM in DVR. The proposed control algorithm was investigated through computer simulation by using PSCAD/EMTDC software. Results: From simulation and experimental results showed the effectiveness and efficiency of the proposed controller based on SVPWM in mitigating voltage sags in low voltage distribution systems. It was concluded that its controller also works well both in balance and unbalance conditions of voltages. Conclusion/Recommendations: The simulation and experimental results of a DVR using PSCAD/EMTDC software based on SVPWM technique showed clearly the performance of the DVR in mitigating voltage sags. The DVR operates without any difficulties to inject the appropriate voltage component to correct rapidly any anomaly in the supply voltage to keep the load voltage balanced and constant at the nominal value.
\end{abstract}

Key words: Voltage source converter, voltage sag, dynamic voltage restore, space vector pulse width modulation

\section{INTRODUCTION}

Power quality problems in industrial applications concern a wide range of disturbances, such as voltage sags and swells, flicker, interruptions, harmonic distortion. Preventing such phenomena is particularly important because of the increasing heavy automation in almost all the industrial processes. High quality in the power supply is needed, since failures due to such disturbances usually have a high impact on production costs.

The voltage sags as defined by IEEE standard 1159, IEEE recommended practice for monitoring electric power quality, is "a decrease in RMS voltage or current at the power frequency for durations from 0.5 cycles to $1 \mathrm{~min}$, reported as the remaining voltage". Typical values are between 0.1 and 0.9 p.u. and typical fault clearing times range from three to thirty cycles depending on the fault current magnitude and the type of over current detection and interruption (IEEE Standards Board, 1995).

Voltage deviations, commonly in the form of voltage sags, can cause severe process disruptions and result in substantial production loss. Several recent surveys attribute that $92 \%$ of the all disturbances in electrical power distribution systems are due to voltage sags (Sabin, 1996).

The Dynamic Voltage Restorer (DVR) (Gosh and Ledwich, 2002; Vilathgamuwa et al., 2002) has been

Corresponding Author: Rosli Omar, Faculty of Electrical, Technical University Malaysia Malacca, Malacca, Malaysia Tel: +60605552224 Fax: 60065552222 
proposed to protect sensitive loads from such voltage sags. The DVR is connected in series with the sensitive load or distribution feeder and is capable of injecting real and reactive power demanded by the load during voltage sag compensation. The output of the DVR inverter is usually provided with an output LC filter to attenuate the harmonic contents appearing in injected voltage. The filter parameters are designed according to certain design aspects such as depth of the sag to be mitigated and the load voltage.

Dynamic voltage restorer operations: A Dynamic Voltage Restorer (DVR) is a recently proposed series connected solid state device that injects voltage into the system in order to regulate the load side voltage. The DVR was first installed in 1996 ( $\mathrm{Li}$ et al., 2001). It is normally installed in a distribution system between the supply and the critical load feeder (Chan, 1998). Its primary function is to rapidly boost up the load-side voltage in the event of a disturbance in order to avoid any power disruption to that load (Buxton, 1998; Sng et al., 2004). There are various circuit topologies and control schemes that can be used to implement a DVR. In addition to voltage sags and swells compensation, DVR can also perform other tasks such as: line voltage harmonics compensation, reduction of transients in voltage and fault current limitations. The general configuration of the DVR consists of an Injection/Booster transformer, a Harmonic filter, a Voltage Source Converter (VSC), DC charging circuit and a Control and Protection system as shown in Fig. 1. In most sag correction techniques, the DVR is required to inject active power into the distribution line during the period of compensation. Hence, the capacity of the energy storage unit can become a limiting factor in the disturbance compensation process especially for sags of long duration.

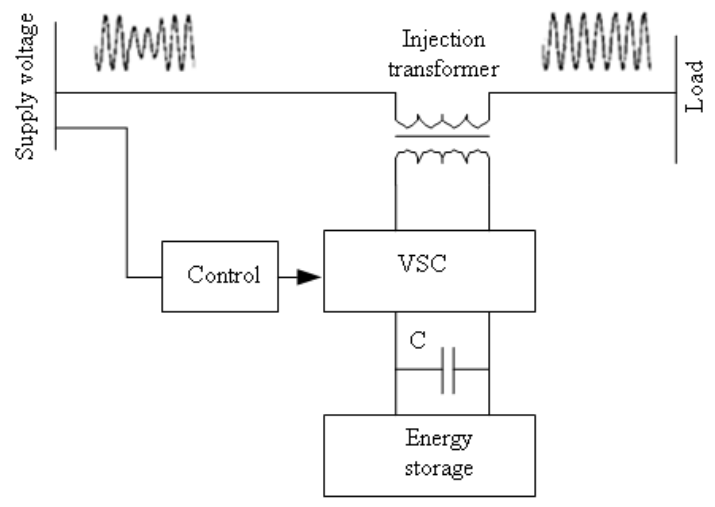

Fig. 1: Typical schematic of a power system compensated by DVR
Objective function: The main objective of this study is to proposed a new approach to the DVR control solution. The proposed controller using space vector modulation techniques obtain higher amplitude modulation indexes if compared with convectional SPWM techniques. Moreover, space vector modulation techniques can be easily implemented using digital processors. Space vector PWM can produce about 15 percent higher output voltage than standard Sinusoidal PWM.

\section{MATERIALS AND METHODS}

Materials of the proposed system: In this study, the materials of the proposed DVR uses a 3-phase Voltage Source Inverter (VSI) configuration. Figure 4a shows the overall system comprised of power system supplying three phase loads through a distribution transformer and a DVR system connected in series to the secondary side of the distribution system. In general a DVR system is comprised of a VSI, an energy storage (i.e., battery) supplying real power, a controller that provides gating signals for VSI control, three singlephase injecting transformers, capacitors that filter out inverter switching harmonic in battery current and LC filter that functions to filter out switching harmonics in the injecting voltages. It is important to point out that LC filter will introduce phase shift in the injecting voltages and complicate the design of the control algorithm.

Proposed method of control system development: The aim of the control scheme is to maintain constant voltage magnitude at the point where a sensitive load is connected, under system disturbances. The control system only measures the r.m.s voltage at the load point, i.e., no reactive power measurements are required. The VSC switching strategy is based on a space vector PWM technique which offers simplicity and good response.

During a sag condition, the correct voltage must be injected so that the load voltage becomes 'normal' again. The reference phasor has three components: phase, frequency and magnitude. During normal network operation all will vary to some degree (Zhan et al., 2001).

In single and three-phase dc/ac power converters, normally it is used Pulse Width Modulation (PWM) technique. However, using techniques such as SPWM presents some problems such as large noise peaks at the multiple numbers of carrier frequencies. In this way, a control method based on space vector PWM is applied to the power converter of the DVR is proposed. 
The block diagram of the control system used is shown in Fig. 4b.

The control system of a DVR plays an important role, with the requirements of fast response in the face of voltage sags and variations in the connected load. Generally, there are two control schemes, open loop (Niesen et al., 2001) and closed loop (Vilathgamuwa et al., 2002), which are used in the DVR applications. This study presents an extensive analysis to develop suitable control strategies for the DVRs. The proposed DVR control system consists of a open loop load voltage using Phase Locked Loop (PLL). The PLL circuit is used to generate a unit sinusoidal wave in phase with mains voltage.

From Fig. 4b The three phase voltages can be converted into $\alpha \beta$ using $\alpha \beta O$ transform:

$$
\left[\begin{array}{c}
\mathrm{V}_{\alpha} \\
\mathrm{V}_{\beta} \\
\mathrm{V}_{0}
\end{array}\right]=\frac{2}{3}\left[\begin{array}{lll}
1 & -1 / 2 & -1 / 2 \\
0 & \sqrt{3} / 2 & -\sqrt{3} / 2 \\
1 / \sqrt{2} & 1 / \sqrt{2} & 1 / \sqrt{2}
\end{array}\right]\left[\begin{array}{c}
\mathrm{V}_{\mathrm{A}} \\
\mathrm{V}_{\mathrm{B}} \\
\mathrm{V}_{\mathrm{C}}
\end{array}\right]
$$

$\alpha \beta$ Co-ordinate system can be transformed into the $\mathrm{dq}$ plane:

$$
\left[\begin{array}{c}
\mathrm{V}_{\mathrm{d}} \\
\mathrm{V}_{\mathrm{q}}
\end{array}\right]=\left[\begin{array}{ll}
\cos \theta & \sin \theta \\
-\sin \theta & \cos \theta
\end{array}\right]\left[\begin{array}{c}
\mathrm{V}_{\alpha} \\
\mathrm{V}_{\beta}
\end{array}\right]
$$

The Space Vector Pulse Width Modulation (SVPWM) method is an advanced, computationintensive PWM method and possibly the best among all the PWM techniques. The circuit model of a typical three-phase voltage source PWM is shown in Fig. 2a. There are eight switch states, the output voltages of the inverter are composed by eight switch states (Zhou and Wang, 2002).

Define eight voltage vectors $\overline{\mathrm{V}_{\mathrm{o}}}=[000], \ldots \ldots . \overline{\mathrm{V}_{7}}=[111]$ corresponding to the switch states $\overline{S_{0}}, \ldots \ldots \ldots . . ., \overline{S_{7}}$, respectively. The lengths of vectors $\overline{\mathrm{V}}_{1}, \ldots \ldots \ldots, \overline{\mathrm{V}}_{6}$ are unity and the lengths of $\overline{\mathrm{V}}_{0}$ and $\overline{\mathrm{V}}_{7}$ are zero and these eight vectors form the voltage vector space as shown in Fig. 2b. The voltage vector space is divided up into six sectors (Vilathgamuwa et al., 2002).

In the vector space, according to the equivalence principle, the following operation rules are obeyed:

$$
\begin{aligned}
& \overline{\mathrm{V}_{1}}=-\overline{\mathrm{V}_{4}} \\
& \overline{\mathrm{V}_{2}}=-\overline{\mathrm{V}_{5}} \\
& \overline{\mathrm{V}_{3}}=-\overline{\mathrm{V}_{6}} \\
& \overline{\mathrm{V}_{0}}=\overline{\mathrm{V}_{7}}=0 \\
& \overline{\mathrm{V}_{1}}+\overline{\mathrm{V}_{3}}+\overline{\mathrm{V}_{5}}=0
\end{aligned}
$$
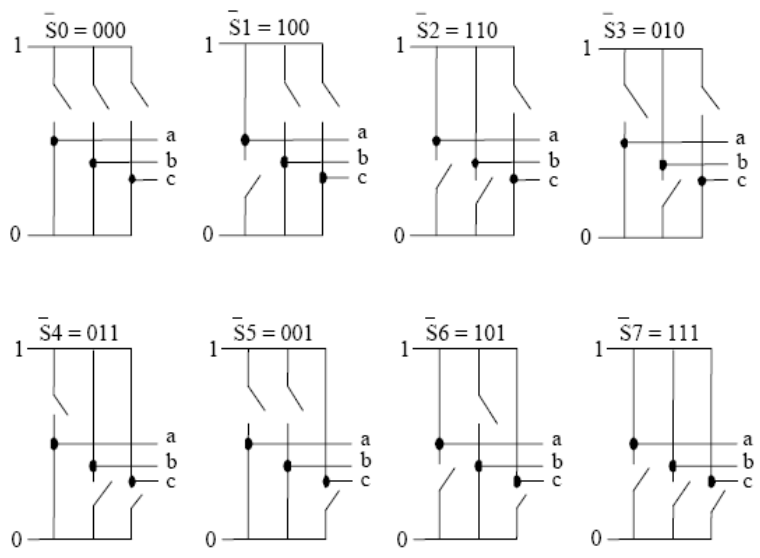

Fig. 2a: Space vector eight switching states

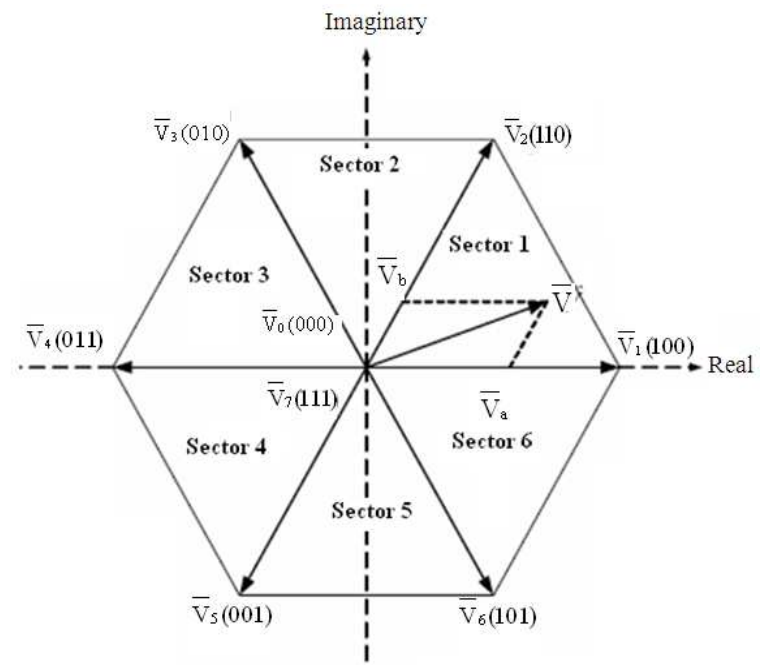

Fig. 2b: Voltage space vector

In one sampling interval, the output voltage vector:

$\overline{\mathrm{V}}(\mathrm{t})=\frac{\mathrm{t}_{0}}{\mathrm{~T}_{\mathrm{s}}} \overline{\mathrm{V}_{0}}+\frac{\mathrm{t}_{1}}{\mathrm{~T}_{\mathrm{s}}} \overline{\mathrm{V}}_{1}+\ldots+\frac{\mathrm{t}_{7}}{\mathrm{~T}_{\mathrm{s}}} \overline{\mathrm{V}_{7}}$

where, $\mathrm{t}_{0}, \mathrm{t}_{1}, \ldots \ldots, \mathrm{t}_{7}$ are the turn-on time of the vectors $\overline{\mathrm{V}}_{1}, \overline{\mathrm{V}_{2}} \ldots \ldots \ldots, \overline{\mathrm{V}_{7}} ; \mathrm{t}_{\mathrm{o}}, \mathrm{t}_{1}, \ldots . ., \mathrm{t}_{7}>0, \sum_{\mathrm{i}=0}^{7} \mathrm{t}_{\mathrm{i}}=\mathrm{T}_{\mathrm{s}}$ and $\mathrm{Ts}=$ Sampling Time and also from Fig. 3 we found that:

$\frac{\mathrm{T}_{2}}{\mathrm{~T}_{\mathrm{s}}}=\overline{\mathrm{V}_{\mathrm{b}}} \quad \frac{\mathrm{T}_{1}}{\mathrm{~T}_{\mathrm{s}}}=\overline{\mathrm{V}_{\mathrm{a}}}$

Figure 3 showing the case of Sector $I$, where $T_{s}$ is half of the PWM period, $T_{1}$ is the duration of Vector 1 
and $\mathrm{T}_{2}$ is the duration of Vector 2 in a half PWM period. The remaining time $T_{\mathrm{s}}-\mathrm{T}_{1}-\mathrm{T}_{2}$ is the duration for the zero vectors. The values of $T_{1}$ and $T_{2}$ are calculated based on the values of $\mathrm{V}_{\text {ref }}$ and $\theta_{\text {ref. }}$. One sampling interval, vector $\overline{\mathrm{V}}$ can be expressed as:

$\overline{\mathrm{V}}=\frac{\mathrm{T}_{1}}{\mathrm{~T}_{\mathrm{s}}} \overline{\mathrm{V}_{1}}+\frac{\mathrm{T}_{2}}{\mathrm{~T}_{\mathrm{s}}} \overline{\mathrm{V}_{2}}+\frac{\mathrm{T}_{7}}{\mathrm{~T}_{\mathrm{s}}} \overline{\mathrm{V}_{7}}+\frac{\mathrm{T}_{0}}{\mathrm{~T}_{\mathrm{s}}} \overline{\mathrm{V}_{0}}$

\section{RESULTS}

A detailed system as shown in Fig. 4a has been modeled by PSCAD/EMTDC to study the efficiency of suggested control strategy. The system parameters and constant value are listed in Table 1 . The results of the most important simulations are represented in Fig. 5 and 6. The load has been assumed linear with power factor pf $=0.85$ lagging and its capacity of 5 KVA.

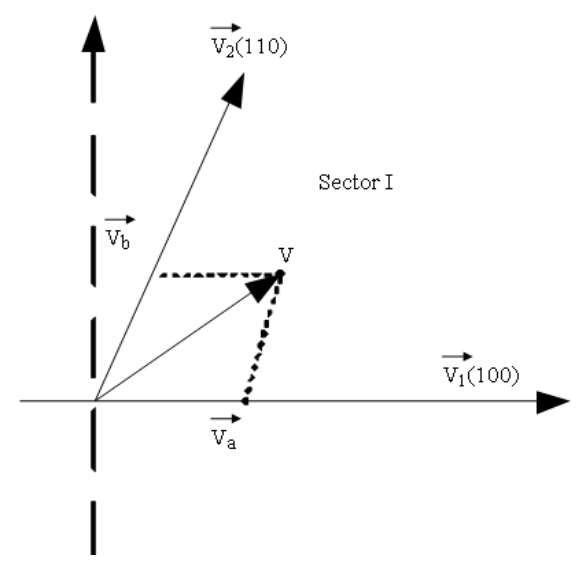

Fig. 3: Reference voltage space vector in sector one

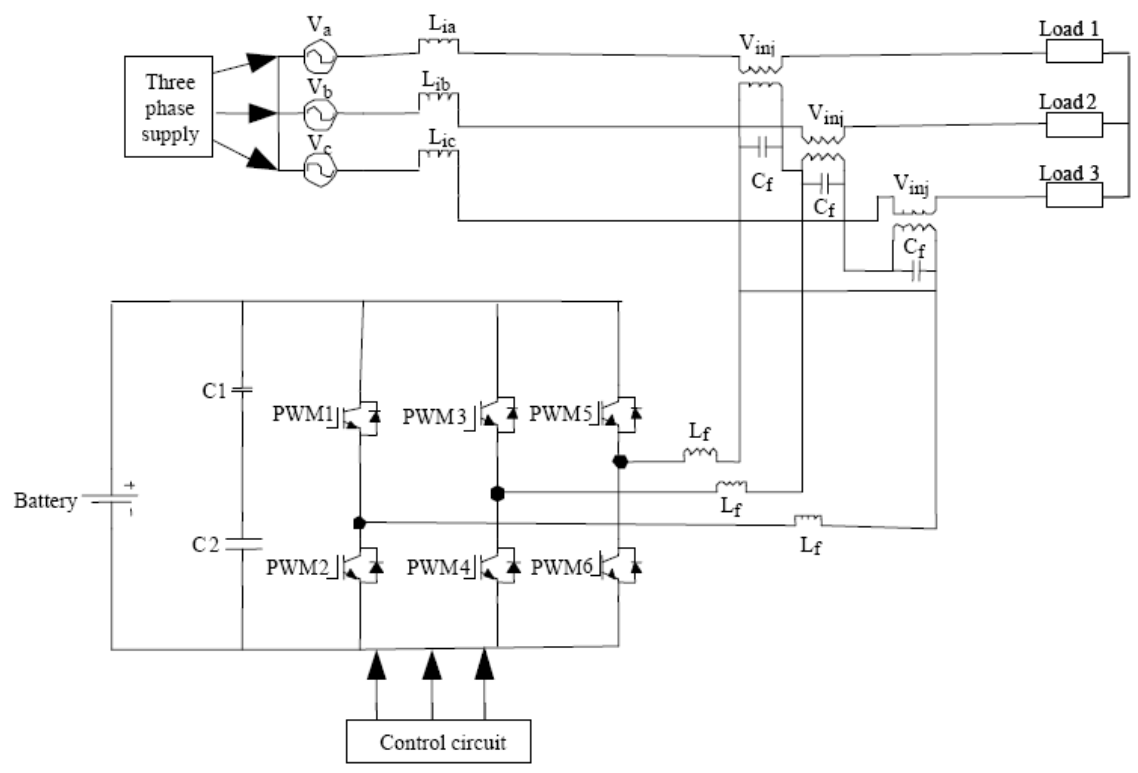

Fig. 4a: Simulated of DVR control

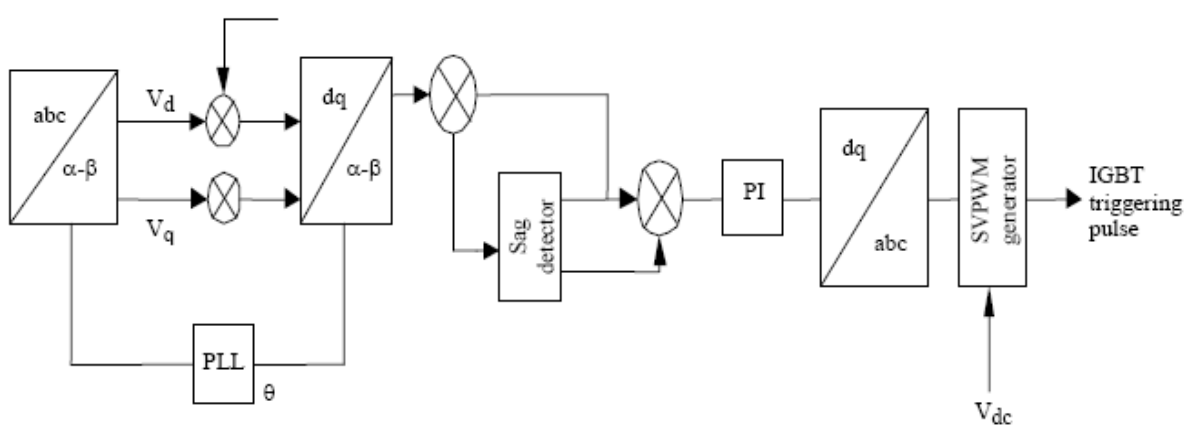

Fig 4b: Control block diagram of DVR implemented 
Am. J. Engg. \& Applied Sci., 3 (1): 42-48, 2010

Table 1 System parameters and constant values

\begin{tabular}{ll}
\hline Main supply voltage per phase & $120 \mathrm{~V}$ \\
Line impedance & $\mathrm{Ls}=0.5 \mathrm{mH}$ \\
& $\mathrm{Rs}=0.1 \Omega$ \\
Series transformer turns ratio & $1: 1$ \\
DC bus voltage & $100 \mathrm{~V}$ \\
Filter inductance & $1 \mathrm{mH}$ \\
Filter capacitance & $1 \mathrm{uF}$ \\
Load resistance & $40 \Omega$ \\
Load inductance & $60 \mathrm{mH}$ \\
Line frequency & $50 \mathrm{~Hz}$ \\
\hline
\end{tabular}

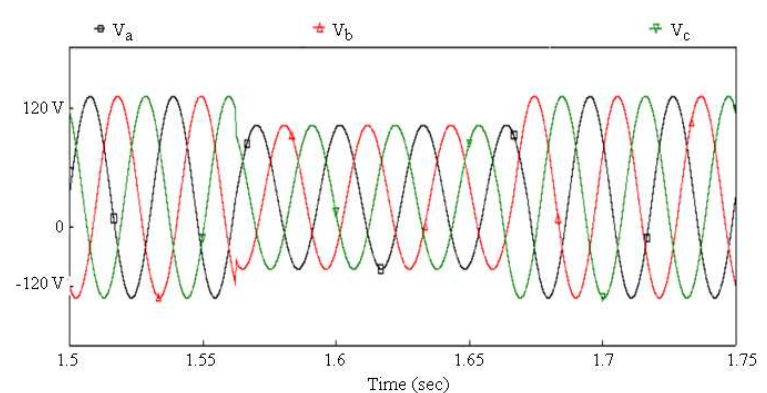

(a)

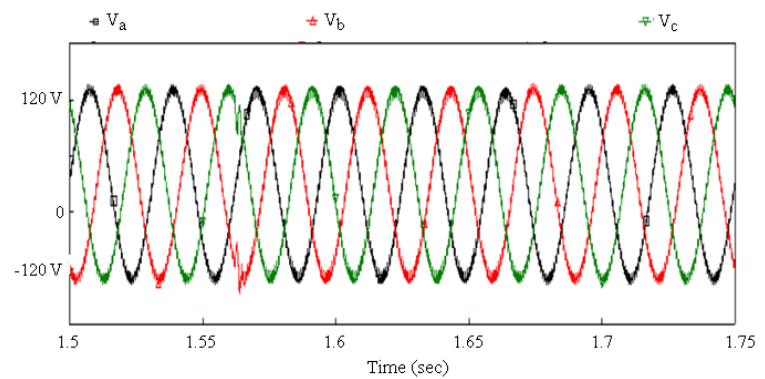

(b)

Fig. 5: Single phase fault. (a) supply voltages; (b) load voltages

\section{DISCUSSION}

In order to understand the performance of the DVR along with control, a simple distribution network as shown in Fig. 3, is implemented. Voltage sags are simulated using PSCAD software. First a case of three phase balanced sag is simulated by connecting a three phase reactance to the basbar. As a result balanced voltage sag is created immediately after a fault as shown in Fig. 5a. Figure 5b shows the load terminal voltages are restored through the compensation by DVR. Next, the performance of DVR for a single phase to ground fault is also investigated. Figure 6a and $b$ show the series of voltages components injected for unbalanced conditions single phase to ground fault is simulated. The DVR load voltages are shown in Fig. 6b. From the results show that the sagged load terminal voltage is restored and help to maintain a balanced and constant load voltage.

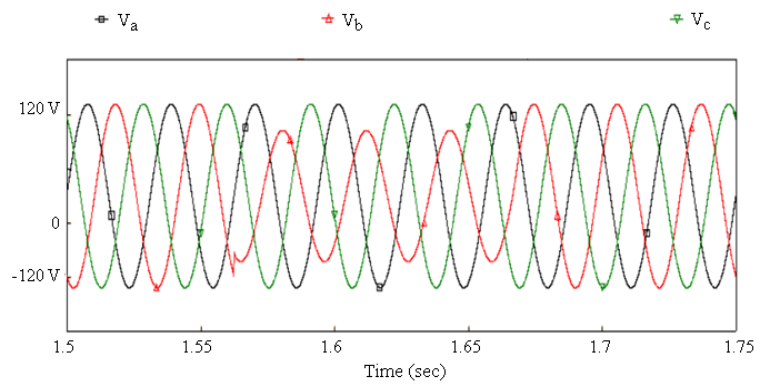

(a)

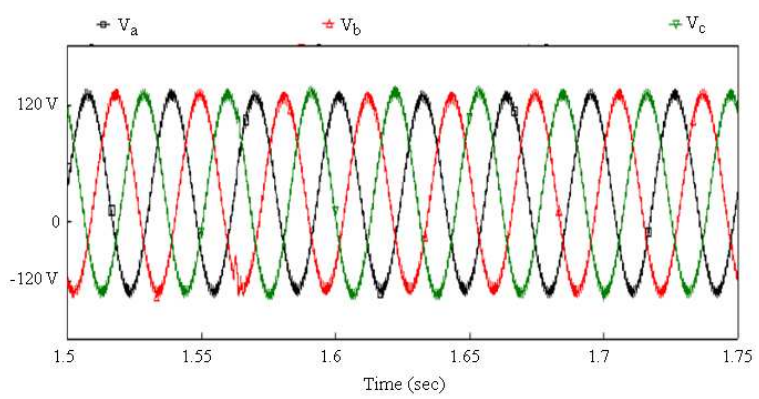

(b)

Fig. 6: Three phase fault. (a) supply voltages, (b) load voltages

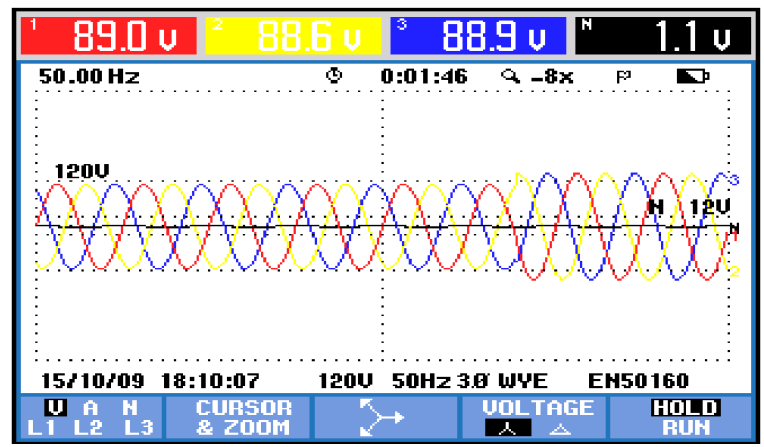

(a)

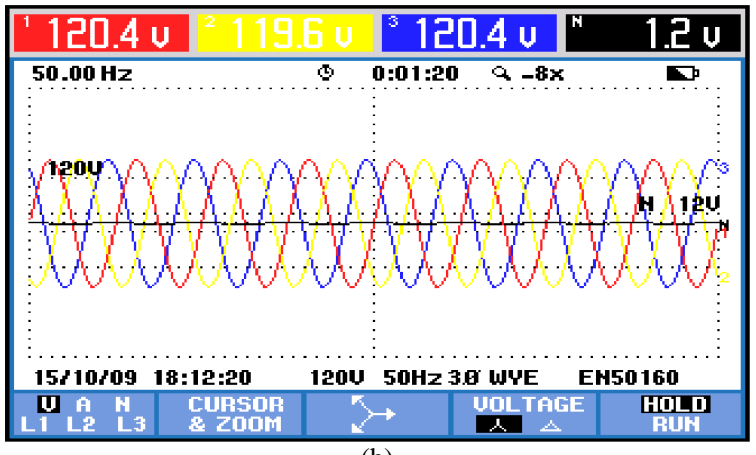

(b)

Fig. 7: Single phase fault. (a) supply voltages, (b) load voltages 

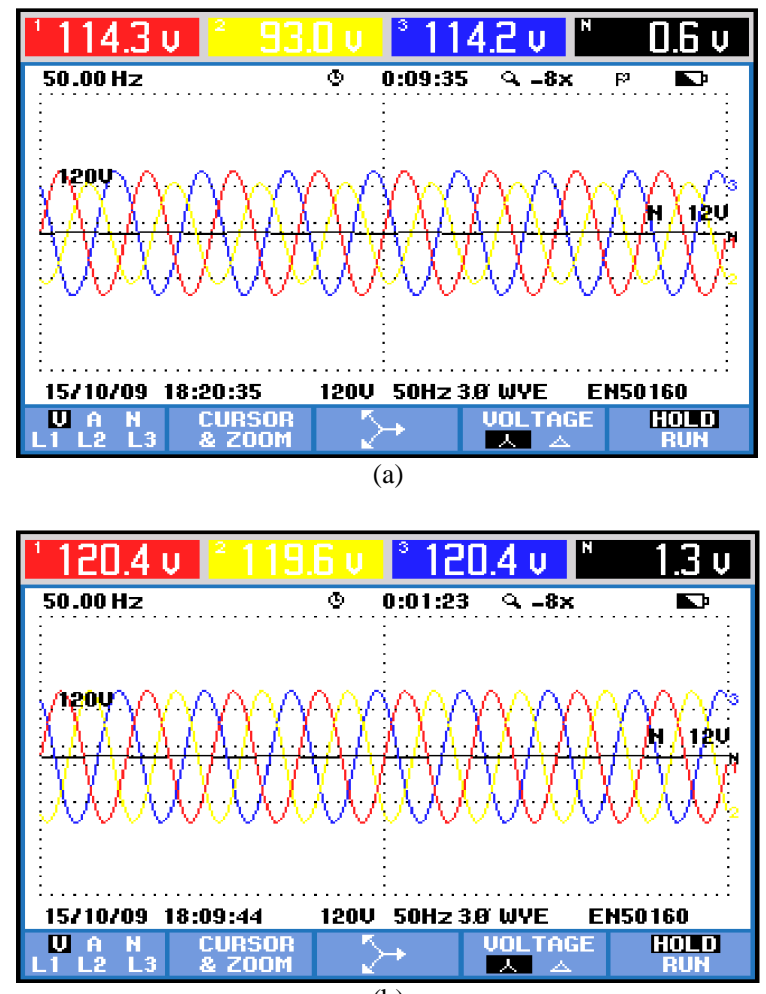

(b)

Fig. 8: Three phase fault. (a) supply voltages, (b) load voltages

A small scale prototype DVR has been built based on schematic in Fig. 1, in order to verify the effectiveness of the DVR operation principles. The experimental results obtained are shown in Fig. 7 and 8.

The low voltage prototype DVR was fed with a programmable AC power source 6560/6590. The prototype is rated to protect a $5 \mathrm{KVA}$ load a 40 voltage sags. The performance during $40 \%$ voltage sag is illustrated in Fig. 7a. Balanced voltage sag is created immediately after a fault as shown in Fig. 7a and b shows the load terminal voltages are restored through the compensation by DVR. Next, the performance of DVR for single phase to ground fault is also investigated. Figure 8a shows the series of voltages components for unbalanced conditions two phase to ground fault. The DVR load voltages are shown in Fig. 8 b. The results show that the sags load terminal voltage is restored and help to maintain a balanced and constant load voltage.

\section{CONCLUSION}

The modeling and simulation of a DVR using PSCAD/EMTDC has been presented. The simulation results showed clearly the performance of the DVR in mitigating voltage sags. The DVR handled both balanced and unbalanced situations without any difficulties and injected the appropriate voltage component to correct rapidly any anomaly in the supply voltage to keep the load voltage balanced and constant at the nominal value. In this study, the DVR has shown the ability to compensate for voltage sags at the grid side, this can be proved through simulation and experimental results.

The efficiency and the effectiveness in voltage sags compensation showed by the DVR makes it an interesting power quality device compared to other custom power devices. The results of the PSCAD/EMTDC simulation and experimental also verify the proposed control algorithm based on Space Vector Pulse Width Modulation (SVPWM) technique to generate the pulses for mitigating voltage sags.

\section{ACKNOWLEDGEMENT}

The researchers wish to thank UM and UTeM for providing grant under grant PS002/2007B for this project.

\section{REFERENCES}

Buxton, R., 1998. Protection from voltage dips with the dynamic voltage restorer. Proceeding of the IEE Half Day Colloquium on Dynamic Voltage Restorers-Replacing those Missing Cycles, Feb. 11-11, IEEE Xplore Press, Glasgow, UK., pp: 3/1$3 / 6$.

http://ieeexplore.ieee.org/iel4/5455/14720/0066816 7.pdf?arnumber $=668167$

Chan, K., 1998. Technical and performance aspects of a dynamic voltage restorer. Proceeding of the IEE Half Day Colloquium on Dynamic Voltage Restorers-Replacing those Missing Cycles, Feb. 11-11, IEEE Xplore Press, Glasgow, UK., pp: 5/1525.

http://ieeexplore.ieee.org/xpl/freeabs_all.jsp?arnum ber $=668170$

Gosh, A. and G. Ledwich, 2002. Compensation of distribution system voltage using DVR. IEEE Trans. Power Deliv., 17: 1030-1036. http://ieeexplore.ieee.org/iel5/61/22435/01046880. pdf?arnumber $=1046880$

IEEE Standards Board, 1995. IEEE Std. 1159-1995: IEEE recommended practice for monitoring electric power quality. http://www.techstreet.com/cgibin/detail?product_id=26423 
Li, B.H., S.S. Choi and D.M. Vilathgamuwa, 2001. Design considerations on the line-side filter used in the dynamic voltage restorer. IEE Proc. Generat. Trans. Distribut., 148: 1-7. DOI: 10.1049/ipgtd:20010017

Niesen, J.G., F. Blaabjerg and N. Mohan, 2001. Control strategies for dynamic voltage restorer compensating voltage sags with phase jump. Proceeding of the 6th Annual IEEE, Applied Power Electronics Conference and Exposition, Mar. 4-8, Anaheim, IEEE Xplore Press, CA, USA., pp: 1267-1273. DOI: 10.1109/APEC.2001.912528

Sabin, D.D., 1996. An assessment of distribution system power quality. Electrical Power Research Institute, EPRI Final Report TR-106294-V2, Palo Alto, CA.

Sng, E.K.K., S.S. Choi and D.M. Vilathga-Muwa, 2004. Analysis of series compensation and DClink voltage controls of a ransformerless selfcharging dynamic voltage restorer. IEEE Trans. Power Deliv., 19: 1511-1518. DOI: 10.1109/TPWRD.2004.829866

Vilathgamuwa, M., A.A.D. Ranjith Pcrcra and S.S. Choi, 2002. Performance improvement of the dynamic voltage restorer with closed-loop load voltage and current-mode control. IEEE Trans. Power Elect., 17: 824-834. DOI: 10.1109/TPEL.2002.802189
Zhan, V.K.R., A. Arulampalam, C. Fitzer, and Barnes, 2001. Dynamic Voltage Restorer based on voltage space vector PWM control. Proceeding of the 16th Annual IEEE, Applied Power Electronics Conference and Exposition, Mar. 4-8, Anaheim, IEEE Xplore Press, CA., USA., pp: 1301-1307. DOI: 10.1109/APEC.2001.912533

Zhou and Wang, 2002. Relationship between space vector Modulation and three phase carrier-based PWM. IEEE Trans. Ind. Elect., 49: 1-11. http://www3.ntu.edu.sg/home/edwwang/jnlpapers/ 00982262.pdf 